\title{
Intracameral vancomycin following cataract surgery: An eleven-year study
}

This article was published in the following Dove Press journal:

Clinical Ophthalmology

16 April 2010

Number of times this article has been viewed

\section{Deepa R Anijeet \\ Prasad Palimar \\ Clive O Peckar}

Department of Ophthalmology, Warrington and Halton NHS

Trust, UK
Correspondence: Deepa R Anijeet I7 Fairfield Drive,Wirral, Merseyside, UKCH48 9YF

Email danijeet@hotmail.com
Aim: To compare the incidences of endophthalmitis after cataract operations before and after introduction of intracameral vancomycin at the end of surgery.

Methods: A retrospective analysis was performed of presumed infectious endophthalmitis after cataract surgery from January 1, 1998 to December 31, 2008. From January 2001, the practice of using intracameral vancomycin at the end of cataract surgery was introduced. The period before introduction of intracameral vancomycin is considered as period $\mathrm{A}$ and that after as period B. The incidences of presumed or culture-proven endophthalmitis during periods $\mathrm{A}$ and $\mathrm{B}$ were compared.

Results: A total of 16,606 cataract surgeries were performed during the study period. The incidence of endophthalmitis per 1000 cataract surgeries was 3.0 during period A and 0.08 during period B. This reduction was statistically significantly (Chi-squared test $36.6, P$ value $<0.0001$ ). The relative risk of developing endophthalmitis without intracameral vancomycin prophylaxis was 38. The absolute risk reduction was 292 cases of endophthalmitis per 100,000 cataract surgeries.

Conclusions: Intracameral vancomycin significantly reduced the incidence of postoperative endophthalmitis after cataract surgery. There is a universal need to adopt this mode of microbial prophylaxis to reduce the burden of endophthalmitis after cataract surgery.

Keywords: endophthalmitis, intracameral vancomycin, cataract surgery

\section{Introduction}

Cataract surgery is the commonest operation performed in health care systems worldwide. The technique has evolved from extracapsular extraction to sutureless phacoemulsification surgery over the past 15 years. Intraocular infection following cataract surgery and lens implantation is a rare but dreaded complication that can have devastating consequences for sight. The Endophthalmitis Vitrectomy Study (EVS) estimated that up to half of patients developing endophthalmitis following cataract surgery had visual acuity worse than $20 / 40$ and $15 \%$ had worse than $5 / 200 .{ }^{1}$ The incidence of endophthalmitis following cataract surgery varies between 0.04 and $0.27 \% .^{2-4}$ Even though several risk factors have been identified, this complication is often unexpected, with variable response to standard treatment. As the number of cataract surgeries is expected to rise with an increasing aging population, the burden of endophthalmitis is likely to rise. A robust preventative strategy is needed to contain this serious complication. The European Society of Cataract and Refractive Surgeons (ESCRS) in a multinational, partially-masked placebo-controlled trial have provided strong evidence for using intracameral antibiotics in preventing postoperative endophthalmitis following cataract 
surgery. ${ }^{5}$ In this study we examined the effect of introduction of intracameral vancomycin at the end of cataract surgery on the incidence of postoperative endophthalmitis in a single eye unit in North West England.

\section{Methods}

The study included all cataract surgeries performed in the Ophthalmic Department at Warrington Hospital in North West England from January 1, 1998 to December 31, 2008. The standard practice of cataract surgery over this period was similar except for the introduction of intracameral vancomycin at the end of cataract surgery from January 2001. In the anesthetic room, 10 minutes prior to cataract surgery, each patient had periocular skin cleaning with $5 \%$ povidone iodine. Two drops of $5 \%$ povidone iodine were instilled into the conjunctival sac at this stage. The surgeon, after scrubbing and draping, used $5 \%$ povidone iodine to cleanse the eyelids and periocular skin. The eyelids including the eye lashes were draped. All cataract surgeries were performed in a dedicated ophthalmic theatre assisted by ophthalmic specialist nurses. Phacoemulsification was performed either using a peristaltic or venturi system. Postoperatively, patients were prescribed prednisolone acetate $1 \%$ two-hourly for two weeks which was then tapered off over a further four weeks. Topical fusidic acid was used for 10 days.

However, in 2000, following a cluster of four cases of endophthalmitis after cataract surgery during a period of three months, the practice of microbial prophylaxis was reviewed. Based on evidence existing at the time, ${ }^{1}$ and following an external investigation and extensive discussions with the hospital infection control team, a decision was made to use vancomycin in a dose of $1 \mathrm{mg}$ in $0.1 \mathrm{~mL}$ of normal saline, to be injected intracamerally into the capsular bag as the final step of cataract surgery.

A case of endophthalmitis was defined as one which presented within six weeks of cataract surgery, with typical clinical findings of intraocular inflammation, reduced vision, and with or without culture-positive vitreous biopsy. ${ }^{1}$ These cases were entered prospectively into a data collection system. The detection and management of a case of endophthalmitis was under the direct supervision of a consultant ophthalmologist. All but two cases of suspected endophthalmitis had emergency vitreous sampling along with intravitreal injection of antibiotics. One case with a visual acuity of perception of light, had pars plana vitrectomy with intravitreal antibiotics as per EVS study. ${ }^{1}$ The vitreous samples were analyzed according to standard practice, with the microbiologist using gram stain and culture on blood agar, chocolate agar, and Sabouraud's agar. Gram stain identified Gram-positive or Gram-negative organisms. Aerobic organisms were identified using incubation of blood and chocolate agar plates at $35^{\circ} \mathrm{C}$ for five days. Anaerobic organisms were identified by incubation of blood agar plate at $35^{\circ} \mathrm{C}$ with increased carbon dioxide in the atmosphere. Sabouraud's media was incubated at $35^{\circ} \mathrm{C}$ for 30 days to identify fungal organisms. Identified organisms had antibiotic sensitivity tests performed to identify susceptibility.

Cases of endophthalmitis following cataract surgery were identified from the data collected on the postoperative complication reporting system in the Ophthalmic Department. The incidences of endophthalmitis before (period A) and after the introduction of intracameral vancomycin after cataract surgery (period B) were calculated. The relative risk, relative risk reduction, and absolute risk reduction were calculated from the data.

\section{Results}

A total of 16,606 cataract surgeries with intraocular lens implantations were performed between January 1, 1998 and December 31, 2008. The distribution of cataract surgeries over the study period is shown in Figure 1. Between January 1, 1998 and December 31, 2000 (period A), prior to introduction of intracameral vancomycin, 3904 cataract surgeries were performed. Thirteen patients developed endophthalmitis during this period. Eleven of the 13 cases of endophthamitis had vitreous sampling and intravitreal antibiotics and two cases had aqueous sampling and intracameral antibiotics. From January 1, 2001 to December 31, 2008 (period B), 12,702 cataract surgeries were performed using intracameral vancomycin at the end of cataract surgery. One patient during this period developed presumed endophthalmitis with a negative vitreous biopsy.

The incidence of endophthalmitis prior to the introduction of intracameral antibiotic prophylaxis was $0.3 \%$. The annual incidence of endophthalmitis during the study period is shown in Figure 2. After the introduction of intracameral antibiotics, the incidence of endophthalmitis dropped to $0.008 \%$ (Table 1). This reduction was statistically significantly (Chisquared test, $36.6 ; P$ value $<0.0001)$. The relative risk of developing endophthalmitis without intracameral antibiotic prophylaxis was 38 (95\% confidence interval [CI]: 7-252). With the use of intracameral vancomycin, the absolute risk reduction was 292 cases of endophthalmitis per 100,000 cataract surgeries. The relative risk reduction was $97 \%$. Five patients with clinical endophthalmitis had a microorganism identified on gram stain or culture. Eight patients had 


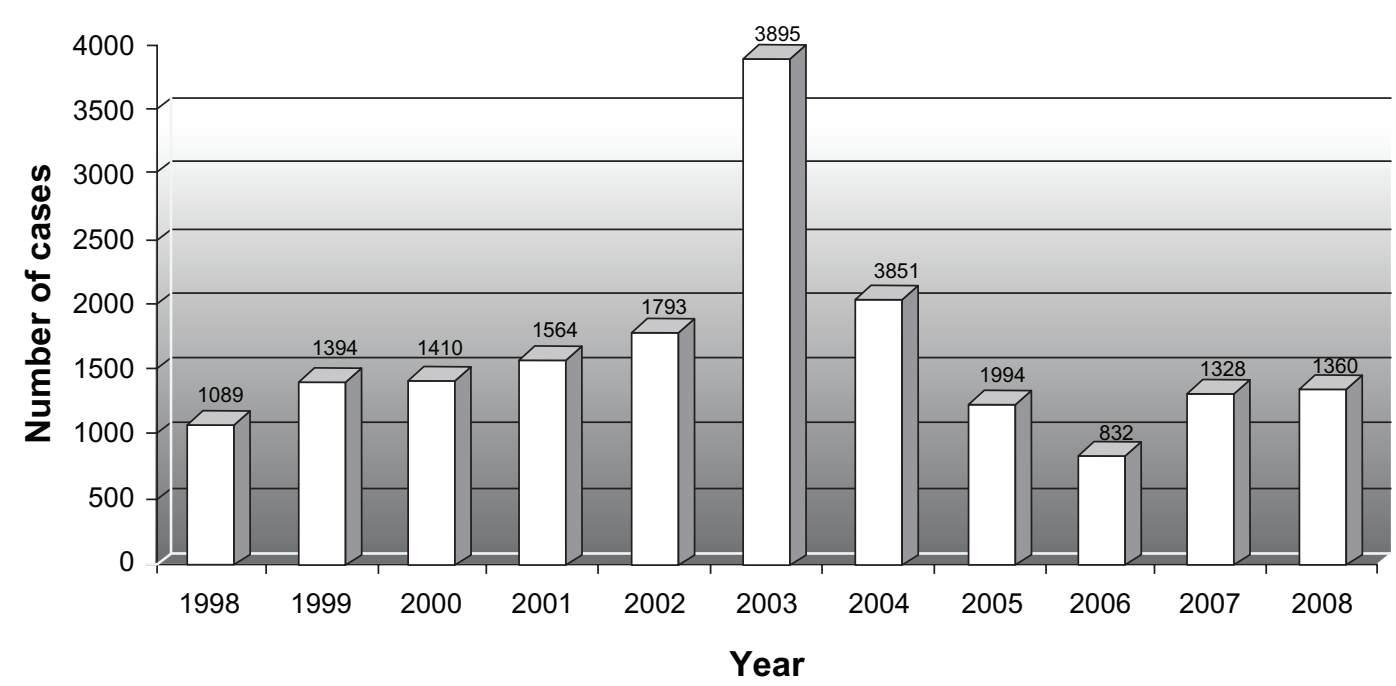

Figure I Distribution of number cataract surgeries performed over the study period.

negative gram stain and culture. Three vitreous samples grew Streptococcus pneumoniae (Table 2).

The experience of surgeons ranged from consultants with more than eight years of experience in performing cataract surgery, to middle-grade surgeons with more than four years of experience, and to junior-grade surgeons with less than four years of experience in performing cataract surgery. The incidence of posterior capsular rupture with vitreous loss as a complication of cataract surgery was similar over the study period at $2.1 \%$ during period $\mathrm{A}$ and $2.2 \%$ during period $\mathrm{B}$. Other microbial prophylactic measures including use of $5 \%$ povidone iodine, and postoperative antibiotics remained unchanged in the two periods.

\section{Discussion}

Dickey et al have shown that anterior segment intraocular surgery frequently introduces bacteria into the anterior chamber. ${ }^{6}$ In $65 \%$ to $100 \%$ of healthy subjects, conjunctiva and adnexa were found to be colonized by microrganisms with the potential to cause endophthalmitis. ${ }^{7,8}$ The EVS found that in $82 \%$ of cases of endophthalmitis, the organism isolated was the same species as that found in the conjunctiva and lids of the same patient. ${ }^{9}$ In the 420 cases of endophthalmitis in the EVS series, $70 \%$ of the isolates were coagulase-negative, Gram-positive staphylococci. As in the EVS study, our study also showed the majority of the culture-positive cases of endophthalmitis to be Gram-positive organisms (Table 2).

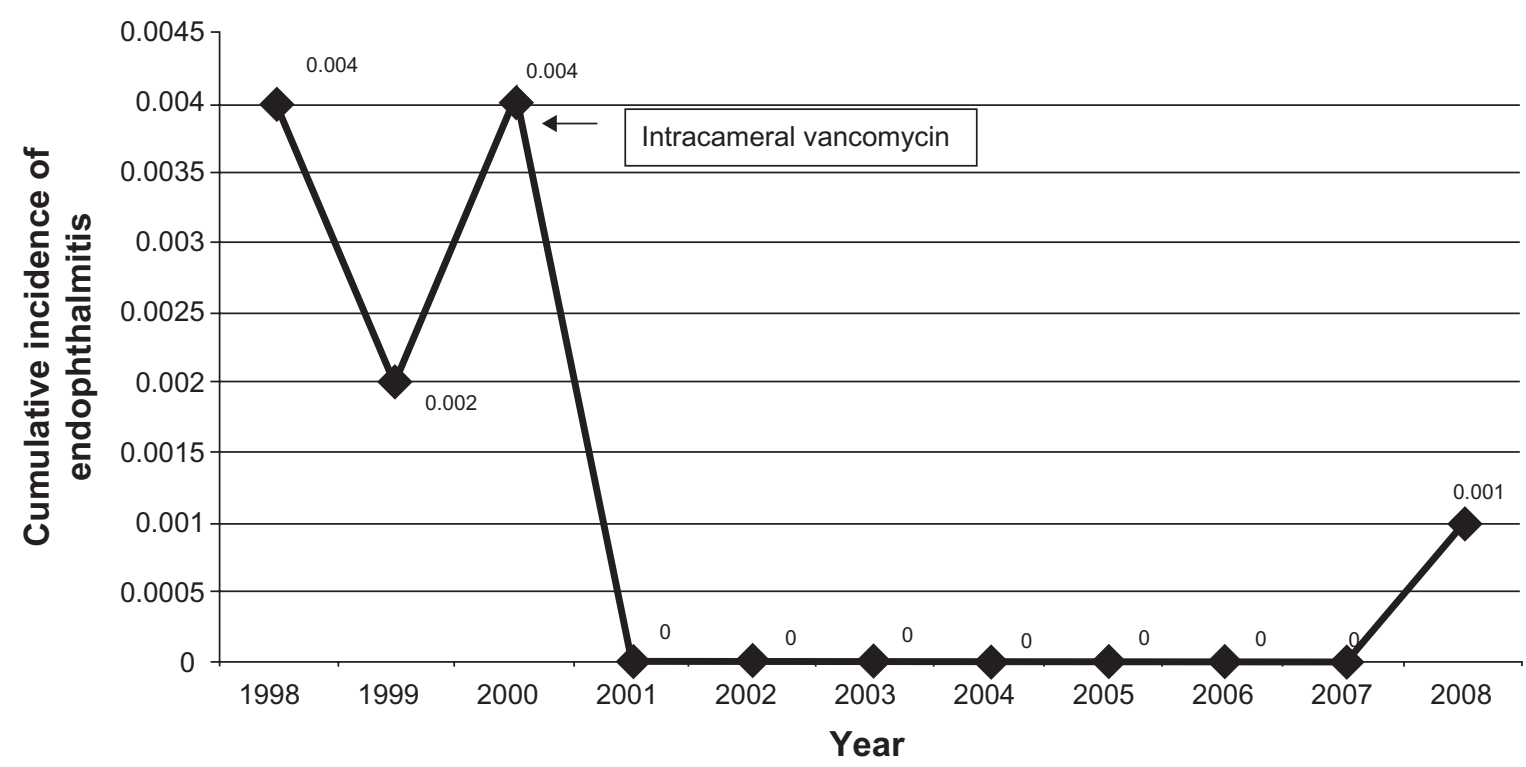

Figure 2 Distribution of cases of endophthalmitis over the study period showing cumulative incidence. 
Table I Incidence of endophthalmitis before and after introduction of intracameral vancomycin prophylaxis

\begin{tabular}{llll}
\hline & $\begin{array}{l}\text { Cataract } \\
\text { surgeries }\end{array}$ & $\begin{array}{l}\text { Endophthalmitis } \\
\text { cases }\end{array}$ & Incidence \\
\hline $\begin{array}{l}\text { Period A 1998-2000 } \\
\text { (Preintracameral }\end{array}$ & 3904 & 13 & 0.3 per 100 \\
$\begin{array}{l}\text { vancomycin) } \\
\begin{array}{l}\text { Period B 2000-2008 } \\
\text { (Postintracameral }\end{array}\end{array}$ & 12702 & 1 & 0.008 \\
vancomycin) & & & per 100 \\
\hline
\end{tabular}

Prophylactic measures to reduce postoperative endophthalmitis after cataract surgery are wide and varied. Several perioperative and postoperative methods have been recognized. Preoperative iodine antisepsis combined with preoperative and postoperative topical antibiotic therapy is considered the standard of care for this purpose. ${ }^{10}$ The last decade has seen the evolution of intracameral antibiotics as a prophylactic measure to prevent postoperative endophthalmitis after cataract surgery, claiming superior effectiveness compared with standard care. Intracameral antibiotics can achieve high concentrations in the anterior chamber but have the potential to cause corneal endothelial toxicity. Yoeruek et al studied the toxic effects of cefuroxime and vancomycin on human corneal endothelial cells, and found them safe in clinically used concentrations. Higher concentrations could cause irreversible cell death. ${ }^{11}$

The choice of intracameral antibiotic prophylaxis appears to be empirical, based on the fact that the majority of isolates are Gram-positive organisms. The first report of intracameral antibiotic prophylaxis was by Peyman et al ${ }^{12}$ using gentamicin. Gimbel reported no case of endophthalmitis in a series of 12,000 patients after using an infusion fluid of gentamicin together with vancomycin during cataract surgery. ${ }^{13}$ Garat et al in their study used intracameral cefazolin because it has a bactericidal effect against Gram-positive organisms. ${ }^{14}$ Montan et al used intracameral cefuroxime for microbial prophylaxis after cataract surgery for similar reasons. They argued that intracameral vancomycin is probably inappropriate due to its poor efficacy against gram-positive enterocooci and its exclusive capacity to combat infections caused by multiresistant Gram-positive bacteria. ${ }^{15}$ For this reason, the Centers for Disease Control and Prevention in the US has cautioned against prophylactic vancomycin in cataract surgery. ${ }^{16}$ Garat et al argued that cefazolin might induce less drug resistance when compared with cefuroxime. Their choice of cefazolin

Table 2 Characteristics of cases of presumed endophthalmitis after cataract surgery over the II-year study period

\begin{tabular}{|c|c|c|c|c|c|c|c|c|c|}
\hline Case & Year & Age & Section & $\begin{array}{l}\text { Intraoperative } \\
\text { complication }\end{array}$ & Suture & $\begin{array}{l}\text { Onset of } \\
\text { symptoms }\end{array}$ & $\begin{array}{l}\text { Intraocular antibiotic } \\
\text { (Intravitreal or } \\
\text { intracameral) }\end{array}$ & $\begin{array}{l}\text { Organism on } \\
\text { gram stain or } \\
\text { culture }\end{array}$ & $\begin{array}{l}\text { Visual } \\
\text { acuity at } \\
\text { last visit }\end{array}$ \\
\hline \multicolumn{10}{|l|}{ Period A } \\
\hline Case I & 1998 & 85 & Clear corneal & Nil & $\mathrm{Nil}$ & 2 days & Nil & Negative & $\mathrm{HM}$ \\
\hline Case 2 & 1998 & 80 & Scleral tunnel & Nil & I0.0 nylon & 9 days & Vancomycin, Ceftazidime & Negative & $6 / 12$ \\
\hline Case 3 & 1998 & 76 & Clear corneal & Nil & Nil & 2 days & Vancomycin, Ceftazidime & $\begin{array}{l}\text { Gram-positive } \\
\text { cocci }\end{array}$ & $6 / 12$ \\
\hline Case 4 & 1998 & 85 & Scleral tunnel & Nil & Nil & I day & Gentamicin,Vancomycin & $\begin{array}{l}\text { Streptococcus } \\
\text { pneumoniae }\end{array}$ & No PL \\
\hline Case 5 & 1999 & 91 & Scleral tunnel & Nil & $\mathrm{Nil}$ & 10 days & Vancomycin, Ceftazidime & Negative & $6 / 60$ \\
\hline Case 6 & 1999 & 65 & Clear corneal & Nil & Nil & 2 days & Cefuroxime,Vancomycin & $\begin{array}{l}\text { Psuedomonas } \\
\text { aeruginosa }\end{array}$ & $6 / 9$ \\
\hline Case 7 & 1999 & 52 & Clear corneal & Nil & Nil & 2 days & Teicoplanin, Ciprofloxacin & Nil & $6 / 12$ \\
\hline Case 8 & 2000 & 80 & Scleral tunnel & Nil & Nil & I day & Vancomycin, Ceftazidime & $\begin{array}{l}\text { Streptococcus } \\
\text { pneumoniae }\end{array}$ & No PL \\
\hline Case 9 & 2000 & 69 & Clear corneal & Nil & I0.0 nylon & 5 days & Teicoplanin, Ciprofloxacin & $\begin{array}{l}\text { Streptococcus } \\
\text { pneumonia }\end{array}$ & $6 / 18$ \\
\hline Case 10 & 2000 & 75 & Scleral tunnel & Nil & $\mathrm{Nil}$ & 6 days & Cefuroxime,Vancomycin & Negative & $6 / 36$ \\
\hline Case II & 2000 & 60 & Scleral tunnel & Nil & Nil & 3 days & Vancomycin, Ceftazidime & Negative & $6 / 9$ \\
\hline Case 12 & 2000 & 78 & Scleral tunnel & Nil & Nil & 14 days & Vancomycin, Ceftazidime & Negative & $6 / 12$ \\
\hline Case 13 & 2000 & 93 & Scleral tunnel & Nil & Nil & 2 days & Vancomycin, Ceftazidime & Negative & No PL \\
\hline \multicolumn{10}{|l|}{ Period B } \\
\hline Case 14 & 2008 & 73 & Clear corneal & Nil & Nil & 2 days & Vancomycin, Ceftazidime & Negative & $6 / 6$ \\
\hline
\end{tabular}


was also based on its cost being $41 \%$ less than that of cefuroxime. ${ }^{17}$ The preliminary report of principal results from a randomized, partially masked, multicentre study by the ESCRS $^{5}$ provided evidence that the risk of contracting endophthalmitis is significantly reduced by an intracameral injection of cefuroxime at the end of surgery. The choice of intracameral antibiotic in the ESCRS study was based on the study by Montan PG et al of the effectiveness and safety of cefuroxime. ${ }^{18,19}$

Our choice of vancomycin in 2000 was guided by the EVS and local consultations. Intracameral vancomycin has been implicated as a cause of cystoid macular edema. Axer-Siegel et al in a randomized controlled trial investigated fluorescein angiogram evidence of cystoid macular edema associated with use of intracameral vancomycin during extracapsular cataract extraction. ${ }^{20}$ They found a significant increase in incidence of cystoid macular edema in the vancomycin group compared with the control group. However, design flaws, long surgical time, and attrition of patients have raised questions about the accuracy of their study results. A more recent randomized controlled trial examined the effects of intracameral vancomycin and gentamicin on macular thickness as measured by ocular coherence tomography. ${ }^{21}$ They found no statistically significant increase in macular thickness in the group that received intracameral vancomycin and gentamicin. In view of the strong evidence in favor of intracameral cefuroxime and concerns about the development of vancomycin resistance, we are reviewing our choice of intracameral antibiotic. With the advent of fourth-generation fluoroquinolones, with their superior antibacterial activity, the choice of antibiotics in the ESCRS study might be outdated. O'Brien et al advocate moxifloxacin as a better choice for intracameral antibiotic prophylaxis. ${ }^{22}$ However, safety studies are available only in animal models.

A recent survey ${ }^{23}$ on antibiotic prophylaxis practice after cataract surgery in the UK raises some interesting issues, given that $37 \%$ of the respondents did not use intracameral antibiotic prophylaxis. The practice of the $61 \%$ who did not respond is unclear. The main criticism of the ESCRS study was the lack of a subconjunctival cefuroxime arm. An uncontrolled but important study in this context demonstrated a threefold reduction in the rate of presumed infectious endophthalmitis when prophylactic practice was changed from subconjunctival to intracameral cefuroxime injection after cataract surgery. ${ }^{24}$ A 2007 survey of American Society of Cataract and Refractive Surgery members found that $77 \%$ were not using intracameral antibiotics, with the majority opting instead for preoperative and postoperative topical antibiotics. ${ }^{25}$ Specifically, fourth-generation fluoroquinolones seemed to be a popular option.

We acknowledge that our study has several limitations due to its retrospective nature. Wound placement, type of intraocular lens, and suture placement are variables that can possibly affect development of endophthalmitis. The above details were not recorded in most of our patient records. Lack of data on these variables could have introduced bias which could potential affect the results. A prospective study would be required to eliminate such bias.

In summary, there is significant research evidence that intracameral antibiotic prophylaxis reduces the incidence of endophthalmitis after cataract surgery. Our study, although retrospective, with an inherent risk of bias, adds support to this body of evidence. The visual, emotional, and financial costs of dealing with endophthalmitis following phacoemulsification are huge. All ophthalmic surgeons should recognize this potential complication and adopt intracameral antibiotics as an essential part of intraocular surgery. Until a commercially available, prediluted, single-dose, licensed antibiotic formulation is available, arrangements with local hospital pharmacies should be made.

\section{Disclosures}

This study was not funded, and the authors report no conflict of interest, either financial or proprietary, in this work.

\section{References}

1. Endophthalmitis Vitrectomy Study Group. Results of the Endopthalmitis Vitrectomy Study: A randomized trial of immediate vitrectomy and of intravenous antibiotics for the treatment of postoperative bacterial endophthalmitis. Arch Ophthalmology. 1995;113:1479-1496.

2. Taban M, Beherens A, Newcomb RL, et al. Acute endophthalmitis following cataract surgery: A systematic review of the literature. Arch Ophthalmol. 2005;123:613-620.

3. Hatch WV, Cernat G, Wong D, Devenyi R, Bell CM. Risk factors for acute endophthalmitis after cataract surgery: A population-based study. Ophthalmology. 2009;116:425-430.

4. Miller JJ, Scott IU, Flynn HW Jr, Smiddy WE, Newton J, Miller D. Acute onset endophthalmitis after cataract surgery (2000-2004): Incidence, clinical settings, and visual acuity outcomes after treatment. Am J Ophthalmol. 2005;139:983-987.

5. Barry P, Seal DV, Gettinby G, Lees F, Peterson M, Revie CW. ESCRS study of prophylaxis of postoperative endophthalmitis after cataract surgery: Preliminary report of principal results from a European multicenter study; the ESCRS Endophthalmitis Study Group. J Cataract Refract Surg. 2006;32:407-410.

6. Dickey JB, Thompson KD, Jay WN. Anterior chamber aspirate cultures after uncomplicated cataract surgery. Am J Ophthalmol. 1991;112: 278-282.

7. Speaker MG, Milch FA, Shah MK, Eisner W, Kreiswirth BN. Role of external bacterial flora in the pathogenesis of acute postoperative endophthalmitis. Ophthalmology. 1991;98:639-649.

8. Boes DA, Lindquist TD, Firtsche TR, Kalima RE. Effects of povidone iodine chemical preparation and saline irrigation on the perlimbal flora. Ophthalmology. 1992;99:1569-1573. 
9. Bannerman TL, Rhoden DL, McAllister SK, Miller JM, Wilson LA. The source of coagulase-negative staphylococci in the Endophthalmitis Vitrectomy Study: A comparison of eyelid and intraocular isolates using pulsed-field gel electrophoresis: The Endophthalmitis Vitrectomy Study Group. Arch Ophthalmol. 1997;115:357-361.

10. Ciulla TA, Starr MB, Masket S. Bacterial endophthalmitis prophylaxis for cataract surgery: An evidence-based update. Ophthalmology. 2002:10913-10924.

11. Yoeruek E, Spitzer MS, Saygili O, et al. Comparison of in vitro safety profiles of vancomycin and cefuroxime on human corneal endothelial cells for intracameral use. J Cataract Refract Surg. 2008;34:2139-2145.

12. Peyman GA, Sathar MI, May DR. Intraocular gentamicin as intraoperative prophylaxis in South India eye camps. Br J Ophthalmol. 1977;61:260-262.

13. Gimbel HV, Sun R, DeBroff BM. Prophylactic intracameral antibiotics during cataract surgery: The incidence of endophthalmitis and corneal endothelial cell loss. Eur J Implant Refract Surg. 1994;6:280-285.

14. Garat M, Moser CL, Alonso-Tarres C, Martin-Baranera M, Alberdi A. Intracameral cefazolin to prevent endophthalmitis in cataract surgery: 3-year retrospective study. J Cataract Refract Surg. 2005;31: 2230-2234.

15. Montan PG, Wejde G, Setterquist H, Rylander M, Zetterstom C. Prophylactic intracameral cefuroxime: Evaluation of safety and kinetics in cataract surgery. J Cataract Refract Surg. 2002;28:982-987.

16. Hospital Infection Control Practices Advisory Committee (HICAC). Recommendations for preventing the spread of vancomycin resistance. Infect Control Hosp Epidemiol. 1995;16:105-113.

17. Garat M, Moser CL, Alonso-Tarres C, Martin-Baranera M, Alonso-Tarres C, Alvarez-Rubio L. Prophylactic intracameral cefazolin after cataract surgery: Endophthalmitis risk reduction and safety results in a 6-year study. J Cataract Refract Surg. 2009;35:637-642.
18. Montan PG, Wejde G, Koranyi G, Rylander M. Prophylactic intracameral cefuroxime: efficacy in preventing endophthalmitis after cataract surgery. J Cataract Refract Surg. 2002;28:977-981.

19. Seal DV, Barry P, Gettinby G, et al. ESCRS study of prophylaxis of postoperative endophthalmitis after cataract surgery: Case for a European multicenter study; the ESCRS Endophthalmitis Study Group. $J$ Cataract Refract Surg. 2006;32:396-406.

20. Axer-Siegel R, Stiebel-Kalish H, Rosenblatt I, Strassmann E, Yassur Y, Weinberger D. Cystoid macular edema after cataract surgery with intraocular vancomycin. Ophthalmology. 1999;106(9):1660-1664.

21. Ball JL, Barrett GD. Prospective randomized controlled trial of the effect of intracameral vancomycin and gentamicin on macular retinal thickness and visual function following cataract surgery. J Cataract Refract Surg. 2006;32(5):789-794.

22. O'Brien TP, Arshinoff SA, Mah FA. Perspectives on antibiotics for postoperative endophthalmitis prophylaxis: Potential role of moxifloxacin. J Cataract Refract Surg. 2007;33:1790-1800.

23. Gore DM, Angunawela RI, Little BC. United Kingdom survey of antibiotic prophylaxis practice after publication of the ESCRS Endophthalmitis Study. J Cataract Refract Surg. 2009;35:770-773.

24. Yui Y, Man T, Morgan SJ, et al. Efficacy of intracameral and subconjunctival cefuroxime in preventing endophthalmitis after cataract surgery. J Cataract Refract Surg. 2008;34:447-451.

25. Chang DF, Braga-Mele R, Mamalis N, et al. Prophylaxis of postoperative endophthalmitis after cataract surgery - results of the 2007 ASCRS member survey. J Cataract Refract Surg. 2007;33:1801-1805.
Clinical Ophthalmology

\section{Publish your work in this journal}

Clinical Ophthalmology is an international, peer-reviewed journal covering all subspecialties within ophthalmology. Key topics include: Optometry; Visual science; Pharmacology and drug therapy in eye diseases; Basic Sciences; Primary and Secondary eye care; Patient Safety and Quality of Care Improvements. This journal is indexed on

\section{Dovepress}

PubMed Central and CAS, and is the official journal of The Society of Clinical Ophthalmology (SCO). The manuscript management system is completely online and includes a very quick and fair peer-review system, which is all easy to use. Visit http://www.dovepress.com/ testimonials.php to read real quotes from published authors. 